\title{
EPA biotech rule reviewed yet again
}

For five years, the US Environmental Protection Agency (EPA; Washington, DC) has been unofficially regulating products under a set of unapproved proposals intended for overseeing smallscale field tests of certain "pesticides" produced by genetically engineered plants. Formal approval has been dogged by critics who insist that ratification of the rules would stifle agricultural biotechnology. Curiously, although researchers from the academic community seem to share that concern (perhaps because they are seeing their freedom of movement curtailed as larger companies call the shots in agbiotech), biotechnology industry representatives seem happy with the status quo.

The long-smoldering debate recently flared again thanks to a coalition of 11 scientific societies comprising, among others, the American Institute of Biological Sciences and the American Societies for Horticulture, Microbiology, and Plant Physiologists. This helped lead to US congressional hearings this spring and (separately) to yet another outside review of the EPA policy proposal, as part of a broader, internally initiated project by the National Research Council (NRC), the operating arm of the National Academy of Sciences (NAS; Washington, DC).

The proposals, which were developed under authority of the Federal Insecticide, Fungicide, and Rodenticide Act (FIFRA) in 1994, have served biotechnology companies as a working guide for overseeing the commercialization of several major, genetically engineered crops-particularly those such as corn, cotton, and potatoes that make Bacillus thuringiensis $(B t)$-based insecticidal proteins. Since 1995, EPA has registered 8 plant pesticides representing 10 pesticide products, with 9 involving $B t$ and the other being a gene from a plant virus to control a virus in potatoes. Development of the FIFRA proposals stemmed from a 1986 decision by the Reagan Administration, which concluded that no new federal laws would be needed to regulate biotechnology. Thus, research and commercial developments from the emerging industry were regulated under the "Coordinated Framework for Biotechnology," and this decision led officials within affected federal agencies to devise rules and guidelines that are consistent with the laws under which those agencies operate.

In addition to looking at the EPA proposals, the NRC committee may reexamine the 1987 NAS Council report, "Introduction of rDNAEngineered Organisms into the Environment." That much-interpreted and widely cited white paper-a much broader statement than the
EPA proposals-has proved the charter (indeed, some might say one of the gospels) for those who practice (or contemplate the impacts of) biotechnology in the great outdoors.

Some critics (mostly environmentalists) of that document, who view it as more a "whitewash" than a white paper, say they welcome a reexamination of critical environmental issues, such as transferable traits, that they claim were sidestepped by the 1987 report. Some of them also hope that this reexamination may lead EPA to conduct fuller environmental risk assessments that some scientists and activists had originally recommended but were not undertaken, by and large because most evaluations have focused on product performance, not impact on the environment and on health.

Meanwhile, members of two subcommittees of the House of Representatives Committee on Agriculture convened hearings to assess the proposed EPA rules. During a hearing late in March, committee members grilled EPA officials and suggested that approval of the EPA proposals could stifle the agricultural side of the biotechnology industry by imposing expensive and cumbersome regulations.

"As a practical matter, [approval of] the rules would not change the manner in which EPA has been regulating these products," says Joseph Panetta of Mycogen (San Diego, CA), who appeared at the hearing on behalf of the American Crop Protection Association (Washington, DC) and the Biotechnology Industry Organization (BIO; Washington, DC). "Federal regulations [including the EPA proposals] are working very well," agrees Alan Goldhammer of BIO.

Although some critics of the EPA proposals suggest they could undermine US international trade efforts, Goldhammer discounts that possibility. "I don't see this review as helping with the entry of US [engineered] agricultural products into European markets," he says. "We think that issue is related broadly to genetically modified organisms, not to any one class of them."

Despite many differences, representatives from industry and universities do agree in their desire to change some of the cumbersome terminology that threads its way through the EPA proposals and to make other changes to the proposals that would streamline EPA review procedures and data requirements. In particular, the current proposals use the central FIFRA-specified term, "pesticide," to refer to $B t$ and other traits whose genes are being engineered into plants.

That terminology "is strongly opposed by the scientific community... [and] is likely to adversely affect public perceptions," says Arthur Kelman, an emeritus plant pathologist at North Carolina State University (Raleigh, NC) and a principal author of the 1987 NAS white paper. Thus, as if borrowing a chapter from the bureaucrat's book of euphemisms, he and other representatives of the research community say they prefer to substitute "plant-expressed protectant" for the EPA-preferred term, "pesticide."

However, the criticisms of EPA by the 11member coalition go beyond legal and scientific argot. The proposed rules are not "scientifically defensible" and could be a "deterrent" for researchers at smaller companies and land grant universities who are working with "minor crops," says James Cook of Washington State University (Pullman, WA).

"I am gravely disappointed that EPA was [originally] dismissive of our concerns and refused to even solicit public comment on our report," says Cook, referring to the coalition's 1996 report, "Appropriate Oversight for the Inherited Traits of Plants for Resistance to Pests."

But EPA's James Aidala says that many of the objections raised may be due to simple misunderstanding of the proposal's provisions, which are actually quite lenient: The EPA proposes several primary exemptions, including naturally occurring traits derived for plants of the same or sexually compatible species, and inherited pest-defense traits that result in physical structure or form. "We believe that the exemptions that would be [formally] established by [approval of] the rules...will minimize EPA's effect on all aspects of agricultural biotechnology," says Aidala. He points out that the exemptions are based on risk considerations and the agency may exempt additional categories.

Kelman maintains that the EPA rules, even with proposed exemptions, fail to be "guided by policies that encourage research and its application, resist unduly burdensome regulations, and also minimize public anxieties about hypothetical hazards."

Attempting to please all sides, however, Aidala adds: "We also believe that consumer acceptance will be key to the ultimate success of products of modern biotechnology, and that consumer acceptance is strongly influenced by confidence that the regulatory agencies will ensure the safety of the products."

Meanwhile, the disposition of the EPA proposed rules is not formally contingent on the outcome of the NRC review. Both a final version of the rules and the NRC review are expected to be completed before the end of this year.

Jeffrey L. Fox 